\title{
AC 2007-18: ASSESSMENT OF PERCEPTUAL MODALITY STYLES
}

\section{Mysore Narayanan, Miami University}

DR. MYSORE NARAYANAN obtained his Ph.D. from the University of Liverpool, England in the area of Electrical and Electronic Engineering. He joined Miami University in 1980 and teaches a wide variety of electrical, electronic and mechanical engineering courses. He has been invited to contribute articles to several encyclopedias and has published and presented dozens of papers at local, regional, national and international conferences. He has also designed, developed, organized and chaired several conferences for Miami University and conference sessions for a variety of organizations. He is a senior member of IEEE and is a member of ASME, SIAM, ASEE and AGU. He is actively involved in CELT activities and regularly participates and presents at the Lilly Conference. He has been the recipient of several Faculty Learning Community awards. He is also very active in assessment activities and has presented more than a dozen papers at various Assessment Institutes. His posters in the areas of Bloom's Taxonomy and Socratic Inquisition have received widespread acclaim from several scholars in the area of Cognitive Science and Educational Methodologies. He has received the Assessment of Critical Thinking Award twice and is currently working towards incorporating writing assessments that enhance students' critical thinking capabilities. 


\title{
Assessment of Perceptual Modality Styles
}

\begin{abstract}
Researchers have shown that systematic use of technology actually helps instructors address perceptual dimensions of learning. Technology should not be viewed just as a growing trend; rather it must be intelligently implemented as a valuable instructional tool that can accommodate diverse learning styles of $21^{\text {st }}$ century students. (Watkins, 2005). It is important to acknowledge that students learn better when alternative modes of information processing are made available at college campuses. Dr. Walter B. Barbe, a nationally known authority in the fields of reading and learning disabilities has shown that perceptual modality styles provides an indication of an individual's dominant learning mode. The degree of processing speed, accuracy and retention that an individual is able to accomplish when encountering information depends upon to what extent the medium in which information presented matches his or her learning style. (Barbe \& Milone 1980 and 1981). In this presentation, the authors describe how they have implemented, incorporated and assessed ideas from Fleming \& Mills' VARK Learning Styles (1992), into their classroom activities and compared them with Hunter Boylan's research findings. This leads to interesting findings and observations. The authors acknowledge the fact that it is very important to create significantly different learning environments, particularly for engineering students.
\end{abstract}

\section{Introduction}

Howard Gardner is the Director of Harvard Project Zero and Professor of Cognition and Education at the Harvard Graduate School of Education. He has received numerous honors and written dozens of books. He was the first American to receive the University of Louisville's Grawemeyer Award in Education. Gardner is best known in educational circles for his theory of multiple intelligences, a critique of the notion that there exists but a single human intelligence that can be assessed by standard psychometric instruments. During the past twenty years, he and colleagues at Project Zero have been working on the design of performance-based assessments, education for understanding, and the use of multiple intelligences to achieve more personalized curriculum, instruction, and assessment. (http://www.pz.harvard.edu/PIs/HG.htm)

\section{Fleming \& Mills' VARK Learning Styles}

VARK is an acronym that stands for Visual, Auditory, Read(includes writing), and Kinesthetic sensory modalities that humans employ for learning and processing information. Fleming and Mills (1992) suggested four categories that seemed to identify students' learning behavior. [Copyright for VARK version is held by Neil D. Fleming, Christchurch, New Zealand and Charles C. Bonwell, Green Mountain, Colorado, USA]. 


\section{Visual (V)}

Some students may learn faster when information is presented to them in the form of diagrams, tables, graphs, charts, etc. Here one may mention the famous proverb: $A$ picture is worth a thousand words. Certain groups of learners prefer when material is in a visual form and for these learners retention is better when they actually see something. This perceptual mode is referred to as Visual mode.

\section{Auditory (A)}

Some other students may be better at the aural category. Learners may prefer being lectured to. These types of learners like to participate in group discussions and would like to talk things through. They enjoy being speakers and also actively participate when others speak. This perceptual mode is referred to as Auditory mode.

\section{$\operatorname{Read}(\boldsymbol{R})$}

A third group of students may be better at the read category. This category implies and includes write category as well. Academics prefer this category of read and write. It is all too well known that instructors ask the students "Read Chapter 7 from the textbook before coming to next class meeting." Some other instructors ask the students to write a 400 word essay about a particular topic. In other words, the input to the student is textbased and the output from the student is text-based. This perceptual mode is referred to as Read mode.

\section{Kinesthetic (K)}

Finally the last group prefers to learn through experience. It could be laboratory experience, clinical experience, simulation, co-op experience, industrial internship experience, service-learning experience, practical training experience, etc. Some people learn only by doing. They need hands-on-training. Here one may want to quote the famous phrase: Practice Makes You Perfect. This perceptual mode is referred to as Kinesthetic mode.

\section{Gardner's Theory of Multiple Intelligences}

According to Howard Gardner, Perceptual Modality refers to the primary way our bodies take in and process information. Commonly, researchers identify visual, auditory, reading and kinesthetic (VARK) styles. (Fleming and Mills, 1992). The field of accelerated learning also relies heavily on modality to explain how learners can process information faster. Howard Gardner established another way of grouping modalities. $\mathrm{He}$ asserts there are at least seven modalities or intelligences that link to our individual styles. (http://www.pz.harvard.edu/PIs/HG.htm) 
Fleming \& Mills' VARK Learning Styles lists only four categories whereas Howard Gardner lists seven styles and suggests humans can be:

$1 \quad$ Verbal-Linguistic

$2 \quad$ Musical

3 Logical-Mathematical

4 Spatial

$5 \quad$ Kinesthetic

6 Interpersonal

7 Intrapersonal

\section{Hunter Boylan's Research Findings}

Hunter R. Boylan is the Chairperson for American Council of Developmental Education Associations. In his book, What Works: Research-Based Best Practices in Developmental Education, Dr. Boylan gives tips for accommodating diversity through instruction. His tips are to train faculty in alterative forms of instruction if they are expected to use diverse instructional methods, administer a learning styles inventory to students as a regular assessment process, share the learning styles information with the faculty to encourage faculty to accommodate dominate learning styles and that students learn best when they have a visual representation and can manipulate objects associated with the concepts. (Appalachian State University's NCDE: National Center for Developmental Education)

Using these suggestions provided by eminent scholars like Howard Gardner and Hunter $\mathrm{R}$. Boylan faculty can introduce many changes into the classroom that can document to have a positive effect on student learning. Research by Dr. Hunter R. Boylan indicates that there are $86 \%$ visual learners, $11 \%$ auditory learners and $3 \%$ tactical-concrete learners. (Boylan 2002).

\section{Ohio State University's TELR:}

At Ohio State University in Columbus Ohio, Technology Enhanced Learning and Research (TELR) reports directly to the Office of the Chief Information Officer (CIO). At the heart of TELR is the TELR Design Team, a team of highly skilled professionals comprising instructional technologists, visual and web designers, web programmers, accessibility specialists, and researchers. The team provides Ohio State's academic community and its external partners with scalable, end-to-end eLearning and visual communication solutions. (http://telr.osu.edu/) 
TELR's mission is to champion the enhancement of teaching and learning through the thoughtful integration of innovative instructional technologies, strategies, and research. TELR opens new realms of possibilities in transforming learning environments for faculty, staff, and students, both on campus and at a distance. In a concerted effort to support these endeavors, TELR encourages exploration and innovation in the use of instructional technologies, provides guidance and solutions in visual and instructional design, expands instructional technology research, and builds partnerships locally and globally. (http://telr.osu.edu/)

There is a very famous and powerful Adage:

"Teach me and I forget."

"Show me and I may remember."

"Involve me and I will learn."

The principle is to change classroom teaching styles from a teaching environment to an atmosphere that promotes learning paradigm. The role of the instructor will be more like a facilitator of a learning environment. The facilitator should try to accommodate $V A R K$ learning styles for the benefit of the learners.

Authors, Alexander W. Astin, Trudy W. Banta, K. Patricia Cross, Elaine El-Khawas, Peter T. Ewell, Pat Hutchings, Theodore J. Marchese, Kay M. McClenney, Marcia Mentkowski, Margaret A. Miller, E. Thomas Moran and Barbara D. Wright developed a document in 1996 under the auspices of the AAHE (American Association for Higher Education) Assessment Forum with support from the Fund for the Improvement of Postsecondary Education with additional support for publication and dissemination from the Exxon Education Foundation. These nine authors have generated a list of nine principles that the authors have reproduced below.

\section{American Association for Higher Education Principles of Good Practice for Assessing Student Learning}

1. The assessment of student learning begins with educational values.

Assessment is not an end in itself but a vehicle for educational improvement. Its effective practice, then, begins with and enacts a vision of the kinds of learning we most value for students and strive to help them achieve. Educational values should drive not only what we choose to assess but also how we do so. Where questions about educational mission and values are skipped over, assessment threatens to be an exercise in measuring what's easy, rather than a process of improving what we really care about.

2. Assessment is most effective when it reflects an understanding of learning as multidimensional, integrated, and revealed in performance over time. Learning is a complex process. It entails not only what students know but what they can do with what they know; it involves not only knowledge and abilities but values, attitudes, and habits of mind that affect both academic success and performance beyond the classroom. Assessment should reflect these understandings by employing a diverse array of methods, 
including those that call for actual performance, using them over time so as to reveal change, growth, and increasing degrees of integration. Such an approach aims for a more complete and accurate picture of learning, and therefore firmer bases for improving our students' educational experience.

3. Assessment works best when the programs it seeks to improve have clear, explicitly stated purposes. Assessment is a goal-oriented process. It entails comparing educational performance with educational purposes and expectations -- those derived from the institution's mission, from faculty intentions in program and course design, and from knowledge of students' own goals. Where program purposes lack specificity or agreement, assessment as a process pushes a campus toward clarity about where to aim and what standards to apply; assessment also prompts attention to where and how program goals will be taught and learned. Clear, shared, implementable goals are the cornerstone for assessment that is focused and useful.

4. Assessment requires attention to outcomes but also and equally to the experiences that lead to those outcomes. Information about outcomes is of high importance; where students "end up" matters greatly. But to improve outcomes, we need to know about student experience along the way -- about the curricula, teaching, and kind of student effort that lead to particular outcomes. Assessment can help us understand which students learn best under what conditions; with such knowledge comes the capacity to improve the whole of their learning.

5. Assessment works best when it is ongoing not episodic. Assessment is a process whose power is cumulative. Though isolated, "one-shot" assessment can be better than none, improvement is best fostered when assessment entails a linked series of activities undertaken over time. This may mean tracking the process of individual students, or of cohorts of students; it may mean collecting the same examples of student performance or using the same instrument semester after semester. The point is to monitor progress toward intended goals in a spirit of continuous improvement. Along the way, the assessment process itself should be evaluated and refined in light of emerging insights.

6. Assessment fosters wider improvement when representatives from across the educational community are involved. Student learning is a campus-wide responsibility, and assessment is a way of enacting that responsibility. Thus, while assessment efforts may start small, the aim over time is to involve people from across the educational community. Faculty play an especially important role, but assessment's questions can't be fully addressed without participation by student-affairs educators, librarians, administrators, and students. Assessment may also involve individuals from beyond the campus (alumni/ae, trustees, employers) whose experience can enrich the sense of appropriate aims and standards for learning. Thus understood, assessment is not a task for small groups of experts but a collaborative activity; its aim is wider, better-informed attention to student learning by all parties with a stake in its improvement. 


\section{Assessment makes a difference when it begins with issues of use and}

illuminates questions that people really care about. Assessment recognizes the value of information in the process of improvement. But to be useful, information must be connected to issues or questions that people really care about. This implies assessment approaches that produce evidence that relevant parties will find credible, suggestive, and applicable to decisions that need to be made. It means thinking in advance about how the information will be used, and by whom. The point of assessment is not to gather data and return "results"; it is a process that starts with the questions of decision-makers, that involves them in the gathering and interpreting of data, and that informs and helps guide continuous improvement.

8. Assessment is most likely to lead to improvement when it is part of a larger set of conditions that promote change. Assessment alone changes little. Its greatest contribution comes on campuses where the quality of teaching and learning is visibly valued and worked at. On such campuses, the push to improve educational performance is a visible and primary goal of leadership; improving the quality of undergraduate education is central to the institution's planning, budgeting, and personnel decisions. On such campuses, information about learning outcomes is seen as an integral part of decision making, and avidly sought.

9. Through assessment, educators meet responsibilities to students and to the public. There is a compelling public stake in education. As educators, we have a responsibility to the publics that support or depend on us to provide information about the ways in which our students meet goals and expectations. But that responsibility goes beyond the reporting of such information; our deeper obligation -- to ourselves, our students, and society -- is to improve. Those to whom educators are accountable have a corresponding obligation to support such attempts at improvement.

\section{Paul Nolting's Research}

Dr. Paul Nolting, Title III Coordinator at Manatee Community College Bradenton, Florida 34207 has compared Student Learning Styles of Developmental Math Students to Faculty Learning Styles. In his publication Dr. Paul Nolting concludes:

"It would be a mistake to think that the only problem under prepared students have is their knowledge base (McCabe, 2003). The idea of learner-centered education is that students must make a connection between the content and their perception of learning (Perin, 2001). To help students better understand their learning, some institutions have attempted to help students define their own learning style by giving them different learning styles inventories." 
Dr. Paul Nolting also comments that:

"By identifying student learning styles and dissemination styles, then students have a better chance to identify with a delivery method that most closely aligns with their ability to learn (McCabe, 2003). Also faculty would have a better understanding on how their students learn in order to modify some of their delivery methods."

\section{Implementation, Assessment and Conclusions}

At Miami University, the author has tried to implement ideas from these scholars into practice using modern technology. This includes the World Wide Web, I.V.D.L. (Interactive Video Distance Learning) in addition to regular and routinely used audio visual techniques. The authors utilize a variety of instructional tools (Lectures, Audiovisual aids, Power Point Presentations, Tutorials, Problem-solving sessions, written research reports, peer group discussions, etc.) to communicate with students who may prefer to have different learning styles. The authors also recommend that students utilize the resources that are readily available at the university, such as Library. Writing Center, etc.

Appendix A shows how Assessment of Perceptual Modality Styles was carried out. The grading was administered using Washington State University's Rubric. A sample of grading scheme is shown in Appendix B \& C. The data obtained was tabulated using a Likert Scale. Several "Primary Traits" or "Characteristics" were identified and assessed. Appendix D documents this using a bar chart. It is desirable to achieve mode values of 5 on all the seven characteristics; however this is probably unrealistic in an undergraduate environment.

It is easily seen from the bar chart that the three "traits"

Characteristic \#2 (Assessment of conclusions, analysis of implications \& addressing consequences),

Characteristic \#3 (Disciplinary perspectives and integration with other relevant issues), and

Characteristic \#6 (Influence of assumptions and identification of appropriate context) all show a respectable mode values of 4 .

However, the other four characteristics show mode values of 3 indicating that there is room for improvement:

Characteristic \#1 (Documentation of good written and oral communication skills) Characteristic \#4 (Presentation of supporting evidence and accurate analysis of data) Characteristics \#5 (Development of hypothesis and defending one's own perspective) and Characteristic \# 7 (Depth of understanding and reformulation of the work assignment) 
Appendix F shows a "VARK” bar chart, based on Fleming and Mills' ideas.

It can been seen that an excellent mode value of 5 was recorded for "Kinesthetic" style of learning. "Reading" style recorded a low score of 2. "Aural" also has a value of 2 whereas "Visual" had a modest value of 4 . The authors agree and understand that these data may vary significantly depending upon subject matter, instructor's delivery styles, material content, discipline etc. It is possible that Kinesthetic Mode of learning may be preferred by students engineering disciplines whereas Reading Mode of learning may be best suited for students in English literature (just for example).

Such assessment data provides the instructor to make appropriate changes in the manner in which the course is developed and may necessitate changes in Instructional Delivery Styles. It is very important to recognize that our data is significantly different from Hunter Boylan's research. A comparison chart is shown in Appendix G. Furthermore it should be recognized that each discipline is different and the difference may be huge and significant. Each instructor's delivery style is different and one may even arrive at two different sets of data for the same subject and topic when two different instructors are involved.

The authors would like to state that Washington State University's Critical Thinking Rubric has proved to be extremely valuable in documenting the effectiveness of systematic use of technology. This has helped the instructors address and assess perceptual dimensions of learning and thereby giving the learning environment facilitators proper guidance for moving in the right direction. The ultimate goal is to deliver information to students in the best possible manner that suits the receiver's optimum learning style.

\section{Acknowledgements}

Dr. Mysore Narayanan is extremely grateful to Dr. Jerry Stonewater for awarding him "Assessment of Critical Thinking - I and II" scholarships. The author also thanks the Center for the Enhancement of Learning and Teaching and Committee for the Enhancement of Learning and Teaching for granting him the award: of "Senior Faculty Learning Community on Miami Plan Assessment and the Scholarship of Teaching” award. Dr. Narayanan also thanks Dr. Milt Cox, Director of Center for the Enhancement of Learning and Teaching at Miami University for his valuable suggestions and guidance. The author is extremely grateful to Dr. Gregg W. Wentzell, Managing Editor for the Journal on Excellence in College Teaching for his invaluable input. The author also thanks Dr. Paul Anderson, Director, Roger and Joyce Howe Center for Writing Excellence for his valuable input. 


\section{APPENDIX A : PERCEPTUAL MODALITY STYLES}

Students were not provided with a questionnaire to fill out.

Rationale: Students are exhausted in filling out forms.

Some researchers are of the opinion that 'questionnaire-fatigue' may result in faulty or skewed data.

If so, how was assessment carried out?

The instructor delivered four content material in four different modes.

Topic 1 was delivered in the Lecture Format. (Aural)

Topic 2 utilized Power Point Slides and other Visual Aids. (Visual)

Topic 3 was left to the students to read, write and submit their findings. (Reading)

Topic 4 was handled like a laboratory, demonstration, discussion, etc. (Kinesthetic)

The four topics chosen were fairly similar in their complexity, although not exactly identical. (The instructor realizes and agrees that one topic may be tougher for the student to understand than another topic, example.)

Later, the students were examined on all the four topics. Instructor graded the test and documented his observations. Grading was holistic and qualitative. No quantitative grade points or percentages were recorded. Grading was recorded based on student's perception, grasp and depth of understanding of the topic.

Rubrics based on Likert Scale (Courtesy of W.S.U.) is shown in Appendix B.

A sample of grading scheme is shown in Appendix C.

Results gathered are represented in a bar chart shown in Appendix D. Assessment of Four Perceptual Modal Styles is shown in Appendix E.

Appendix F shows the "VARK" bar chart based on Fleming and Mills' ideas.

A comparison between Dr. Boylan's research and author's data is shown in Appendix G.

[Copyright for VARK version is held by Neil D. Fleming, Christchurch, New Zealand and Charles C. Bonwell, Green Mountain, Colorado, USA]. 


\section{APPENDIX B (Rubrics courtesy of W S U, Pullman, WA)}

\section{Rubrics based on Likert Scale}

5

Has demonstrated excellence.
Has provided documentation.
Evidence of critical thinking ability.
Very good performance

3

Has demonstrated competency.

Adequate documentation.

Critical thinking ability exists.

Acceptable performance.

1

Poor, unacceptable performance.

Lacks critical thinking ability.
Has analyzed important data precisely.

Has answered key questions correctly.

Has addressed problems effectively.

Has evaluated material with proper insight.

Has used deductive reasoning skills.

Has used inductive reasoning skills.

Has employed problem solving skills.

Has discussed consequences of decisions.

Has been consistent with inference.

Data analysis can be improved.

More effort to address key questions.

Need to address problems effectively.

Expand on evaluating material.

Improve deductive reasoning skills.

Improve inductive reasoning skills.

Problem solving skills need honing.

Must discuss consequences of decisions.

Has been vague with inference.

Absence of analytical skills.

Answers questions incorrectly.

Addresses problems superficially.

Lacks documentation.

Inability to evaluate material.

Shows no deductive reasoning power.

Inductive reasoning power non existent.

Poor problem solving skills

Unaware of consequences of decisions.

Unable to draw conclusions. 
Assessment of Perceptual Modality Styles

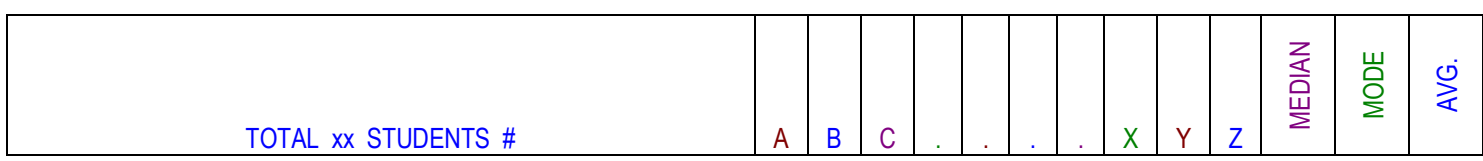

THE CRITICAL THINKING RUBRIC

RUBRIC COURTESY OF W. S. U.

WASHINGTON STATE UNIVERSITY

PULLMAN, WA. 99164.

LIKERT SCALE WEIGHT DISTRIBUTION:

(1: Strongly Disagree; 5 : Strongly Agree)

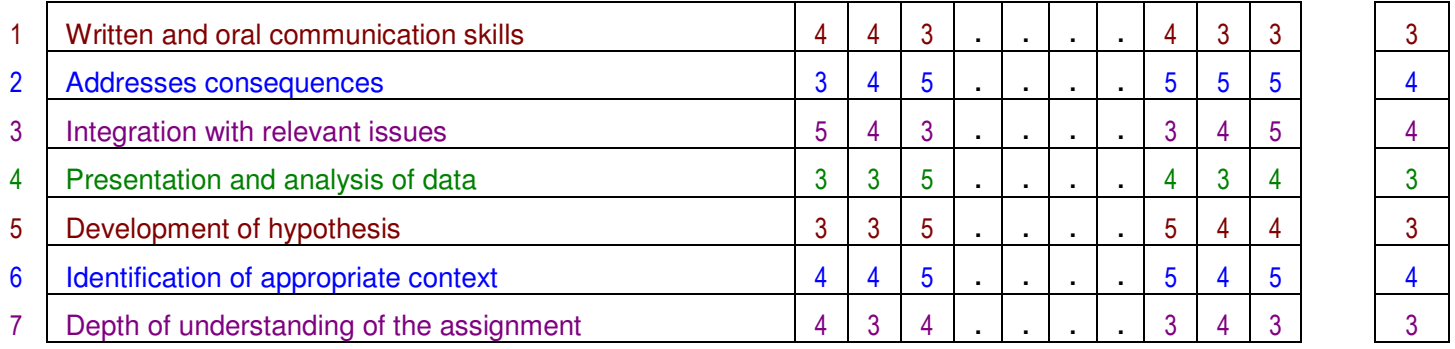

Data Collected by: Mysore Narayanan

The data collected are normally displayed in a bar chart.

It should be observed that the data collected are ordinal. This indicates that they have an inherent order or sequence. It must be interpreted carefully. The data is not continuous.

Therefore it is not appropriate to create a histogram. Mean values do not have any meaning for interpretation. Furthermore Standard Deviation does not convey anything.

Reference: http://www.icbl.hw.ac.uk/ltdi/cookbook/info_likert_scale/

Descriptive Techniques (Likert Evaluation Cookbook 2004)

The data are normally summarized using a median or a mode.

The author prefers mode because it is considered to be the most appropriate for this type of data analysis. 
APPENDIX D (Rubrics courtesy of W S U, Pullman, WA)

1. Documentation of good written and oral communication skills

2. Assessment of conclusions, analysis of implications \& addressing consequences.

3. Disciplinary perspectives and integration with other relevant issues.

4. Presentation of supporting evidence and accurate analysis of data.

5. Development of hypothesis and defending one's own perspective.

6. Influence of assumptions and identification of appropriate context.

7. Depth of understanding and reformulation of the work assignment.

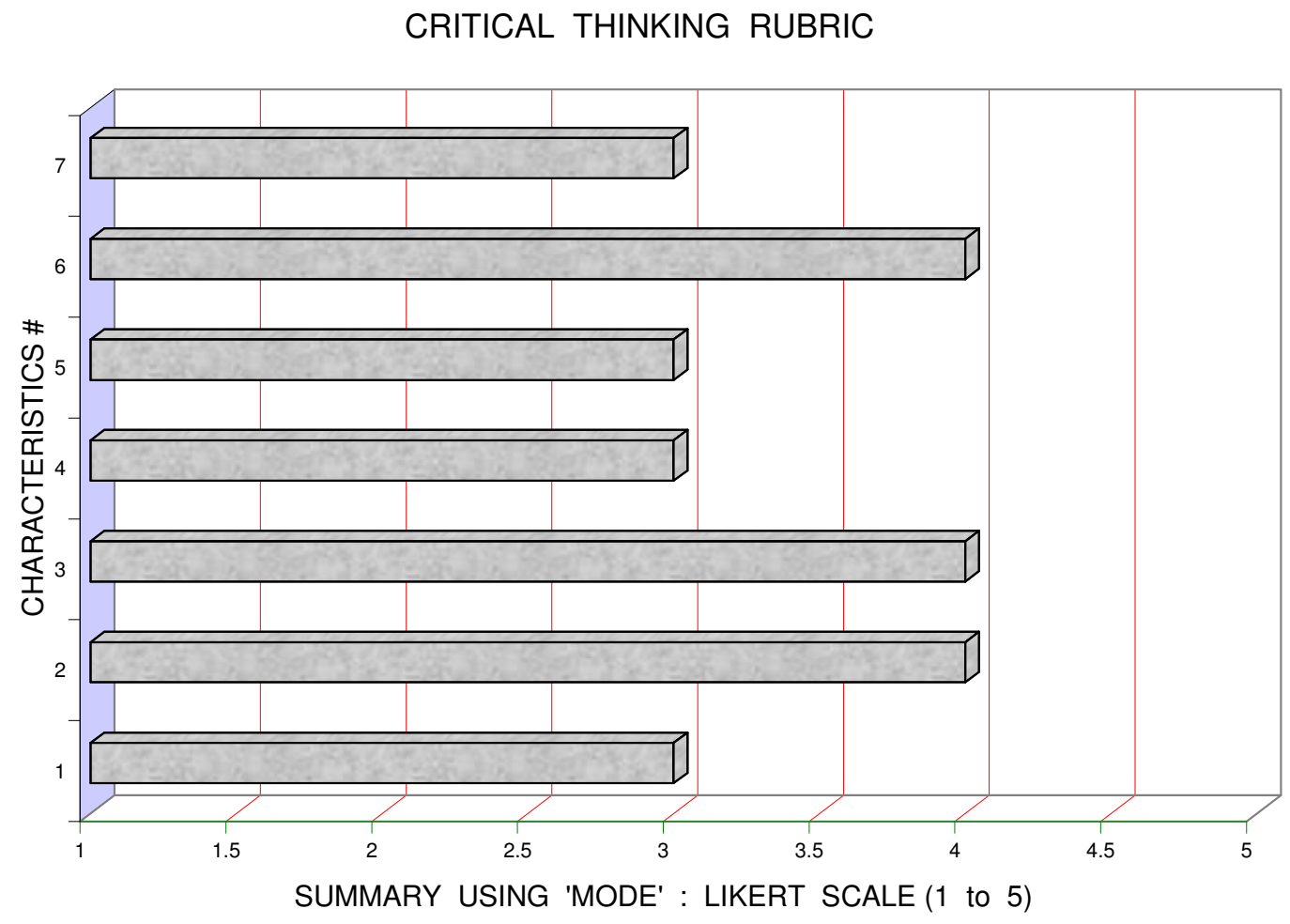




\section{APPENDIX E (Rubrics courtesy of W S U, Pullman, WA)}

Source: Fleming, N. D. \& Mills, C. (1992).VARK a guide to learning styles. http://www.vark-learn.com/English/index.asp

Assessment of Four

Perceptual Modality Styles

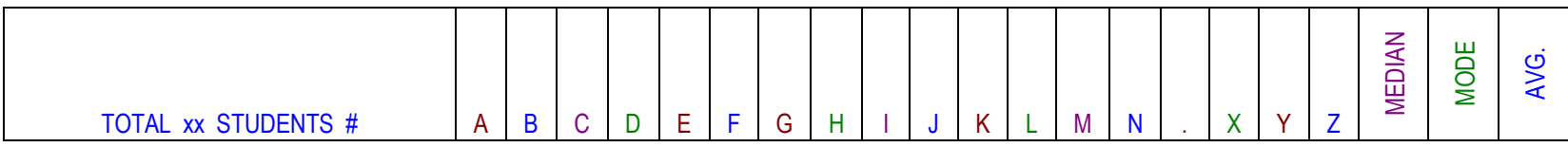

RUBRIC COURTESY OF W. S. U. WASHINGTON STATE UNIVERSITY

PULLMAN, WA. 99164.

LIKERT SCALE WEIGHT DISTRIBUTION

(1: Strongly Disagree; 5 : Strongly Agree)

\begin{tabular}{l|l|}
\cline { 3 - 3 } 1 & Visual \\
\cline { 3 - 3 } 3 & Aural \\
\cline { 3 - 3 } 3 & Reading \\
& Kinesthetic \\
\hline & Data Collected by: \\
Mysore Narayanan.
\end{tabular}

It should be observed that the data collected are ordinal. This indicates that they have an inherent order or sequence. It must be interpreted carefully. The data is not continuous.

Therefore it is not appropriate to create a histogram. Mean values do not have any meaning for interpretation.

Furthermore Standard Deviation does not convey anything.

Reference: http://www.icbl.hw.ac.uk/ltdi/cookbook/info_likert_scale/

Descriptive Techniques (Likert Evaluation

Cookbook 2004)

The data are normally summarized using a median or a mode.

The author prefers mode because it is considered to be the most appropriate for this type of data analysis.

The data collected are normally displayed in a bar chart. 


\section{APPENDIX F}

Source: Fleming, N. D. \& Mills, C. (1992).VARK a guide to learning styles.

http://www.vark-learn.com/English/index.asp

\section{Kinesthetic \\ 3. Reading \\ 2. Aural \\ 1. Visual}

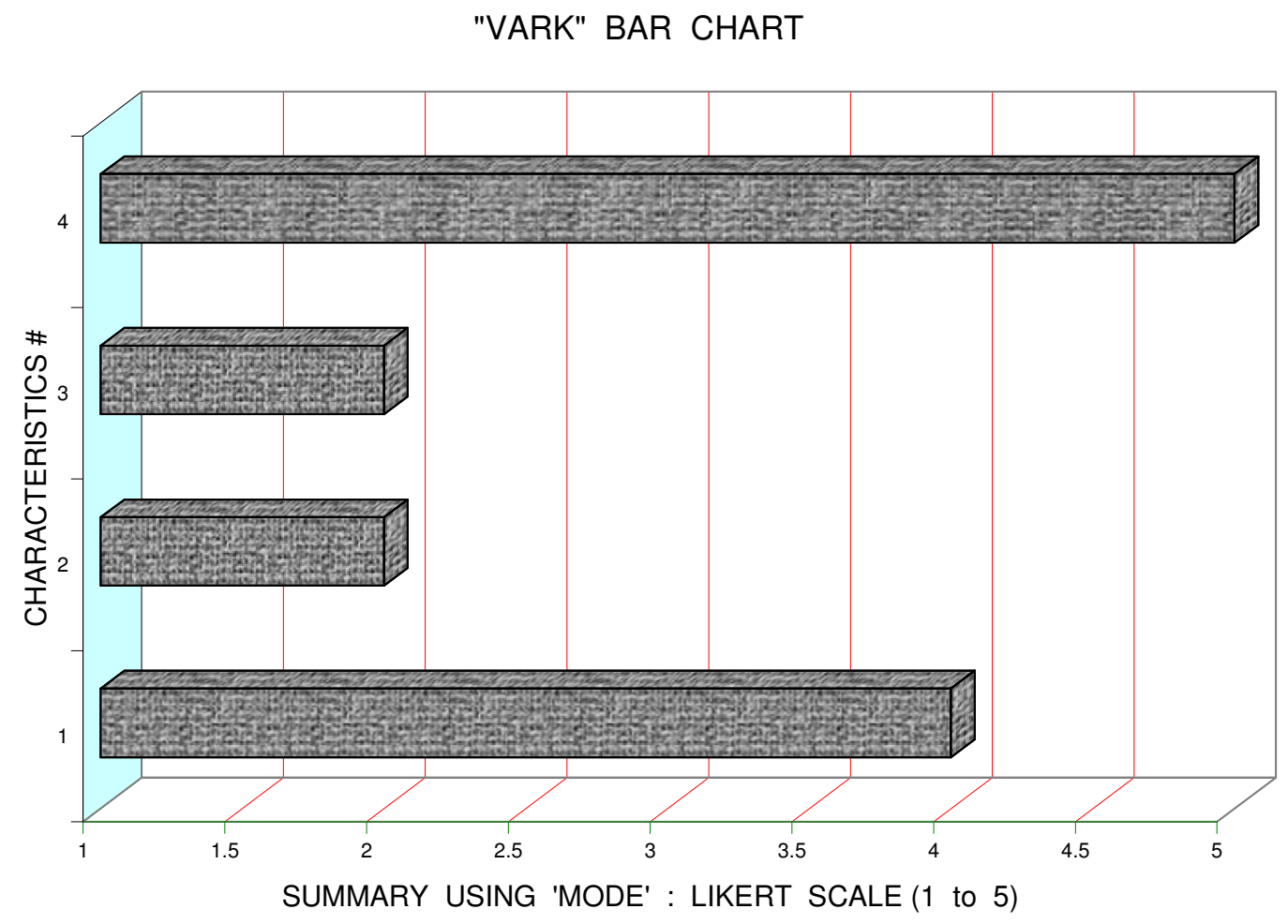

$\mathbb{D}$
$\stackrel{0}{0}$
$\vec{D}$
$\vec{N}$
$\mathbb{0}$
0
$\overrightarrow{0}$ 
APPENDIX G (Comparison between Hunter Boylan's Research and Author's data)

Source: Fleming, N. D. \& Mills, C. (1992).VARK a guide to learning styles. http://www.vark-learn.com/English/index.asp

\begin{tabular}{|c|c|c|}
\hline Research by & & $\begin{array}{c}\text { Author's } \\
\text { Data }\end{array}$ \\
\hline $\begin{array}{l}\text { Dr. Hunter R. } \\
\text { Boylan } \\
\text { (Boylan 2002) }\end{array}$ & & \\
\hline $86 \%$ & Visual & Mode $=4$ \\
\hline \multirow[t]{3}{*}{$11 \%$} & Auditory & Mode $=2$ \\
\hline & Reading & Mode $=2$ \\
\hline & Kinesthetic & Mode $=5$ \\
\hline $3 \%$ & $\begin{array}{l}\text { Tactical- } \\
\text { Concrete }\end{array}$ & \\
\hline
\end{tabular}

Boylan, H. R. (2002). What Works: Research-Based Best Practices in Developmental Education.

Boone, NC: National Center for Developmental Education.

Sometimes, in engineering disciplines "Kinesthetic" and "Visual" may slightly overlap.

In a laboratory setting, the students can actually "see and observe" certain operations when they "perform" experiments.

See and observe may be interpreted as visual. Perform may be interpreted as Kinesthetic.

Therefore, a laboratory session of 2 or 3 hours' duration can be classified as Visual or Kinesthetic. 


\section{References:}

1. Barbe, Walter B. , Milone, Michael N., Jr. (1980). Modality. Instructor, 89, 44-47.

2. Baxter-Magolda, M. (1992). Knowing and reasoning in College: Gender related patterns in student development. San Francisco: Jossey-Bass.

3. Boylan, H. R. (2002). What Works: Research-Based Best Practices in Developmental Education. Boone, NC: National Center for Developmental Education.

4. Boylan, H. R. (1999). Exploring alternatives to remediation. Journal of Developmental Education, 22(3), 2-4, 6, 8, 10.

5. Boylan, H. R. (1999). Harvard Symposium 2000: Developmental education: Demographics, outcomes, and activities. Journal of Developmental Education, 23(2), 2-4, 6, 8.

6. Boylan, H., Bliss, L., \& Bonham, B. (1997). Program components and their relationship to student success. Journal of Developmental Education, 20(3), 2-4, 6, 8.

7. Boylan, H.R., Bonham, B.S., Clark-Keefe, K., Drewes, S., \& Saxon, D.P. (2004). Forging new partnerships. Adult and developmental education in community colleges. Working Paper 8. CAAL Community College Series. New York, NY: Council for Advancement of Adult Literacy.

8. Brown, J. F., \& Cooper, R. M. (1976). Learning Styles Inventory. Freeport, New York. Educational Activities Software.

9. Claxton, C.S. \& Smith, W.F. (1984). Learning styles: Implications for improving educational practices. ASHE-ERIC Higher Education Report No. 4, Washington, DC: The George Washington University, School of Education and Human Development.

10. Dunn, R. \& Dunn, K. (1979). Learning Styles/Teaching Styles: Should They... Can They ... Be Matched. Educational Leadership, January.

11. Fleming, N. D. \& Mills, C. (1992).VARK a guide to learning styles. http://www.vark-learn.com/English/index.asp

12. Gardner, Howard (1993). Frames of mind: The Theory of Multiple Intelligences (10th anniversary edition). New York: Basic Books.

13. Grasha, A.F. (1996). Teaching with style. Pittsburgh, PA: Alliance Publishers

14. Kolb (1985) Learning Styles Inventory. Boston, MA: TRG Training Resource Group.

15. Lage, M. J.,Platt, G. J. \& Treglia, M. (2000). Inverting the classroom: A gateway to creating an inclusive learning environment. Journal of Economic Education.

16. Lawrence, G. (1982). People types and tiger stripes. [Second edition]. Gainesville, FL: CAPT

17. McCabe, R. H. (2003). Yes We Can! A Community College Guide For Developing America's Under prepared, Phoenix, AZ: League of Innovation in the Community College.

18. McCarthy, B. (1995). 4MATin Action. Barrington, IL. 
19. Moallem, M. (2001). The implications of the research literature on learning styles for the design and development of a Web-based course. Presented at the AECT 2001 Annual Conference.

20. Perin, D. (2001 August/September). Making Remediation More Learner-Centered. Community College Journal, 69(5), 26-33.

21. Shelton, Leslie; Conan, Joan Sheldon and Fulghum-Nutters, Holly (1992). Honoring Diversity. A Multidimensional Learning Model for Adults. Sacramento, California: California State Library Foundation.

22. Watkins, Angela Farris (2005). Using Learning Styles in College Thinking. Journal on Excellence in College Teaching. 16(3), 83-101.

23. $\quad$ http://telr.osu.edu

24. $\quad$ http://wsuctproject.wsu.edu/ctr.htm

25. http://www.pz.harvard.edu/PIs/HG.htm

26. http://www.icbl.hw.ac.uk/ltdi/cookbook/info_likert_scale/

27. 